Portland State University

PDXScholar

Summer 2021

\title{
The Psychedelic Renaissance: a Convergence of Indigenous Knowledge and Science
}

Ronan K. Peck

Portland State University

Follow this and additional works at: https://pdxscholar.library.pdx.edu/honorstheses

Part of the Alternative and Complementary Medicine Commons, Multicultural Psychology Commons, and the Other Psychology Commons

Let us know how access to this document benefits you.

\section{Recommended Citation}

Peck, Ronan K., "The Psychedelic Renaissance: a Convergence of Indigenous Knowledge and Science" (2021). University Honors Theses. Paper 1139.

https://doi.org/10.15760/honors.1171

This Thesis is brought to you for free and open access. It has been accepted for inclusion in University Honors Theses by an authorized administrator of PDXScholar. Please contact us if we can make this document more accessible: pdxscholar@pdx.edu. 


\title{
The Psychedelic Renaissance:
}

\section{a convergence of Indigenous knowledge and science}

\author{
by \\ Ronan K. Peck
}

An undergraduate honors thesis submitted in partial fulfillment of the requirements for the degree of Bachelor of Arts

in

University Honors

and

Psychology

Thesis Advisor

Dr. Bill Griesar

Portland State University 


\begin{abstract}
In recent times, psychedelics are back in the public eye, mostly through scientific intrigue about their healing potential. In the past decade, hundreds of studies have been conducted to explore the possible benefits, or risks, that these substances could bring to people - and there is great potential being found. This is the psychedelic renaissance, and with this phenomenon in full swing, it is important to take a step back and look at the full picture of our history with these substances. By doing so, it starts to become clear that psychedelics have guided human perception and understanding of our world for a very long time. The recognition of how important these substances are did not start last year or within the decade, or even back in the $20^{\text {th }}$ century with Albert Hoffman's discovery of LSD. Humankind have been utilizing these substances for thousands of years - and the spiritual significance they contain for Indigenous people is almost unfathomable. That being said, the current psychedelic renaissance is being guided almost entirely by science and academia - as it has been since the colonization of Indigenous people, followed up by a Western takeover of the psychedelic healing paradigm starting in the late 1940's. This literature review aims to catalog and make clear the role of Indigenous practices within psychedelic healing, and explores how a White-dominant scientific understanding of the same phenomenon has overshadowed these previous understandings, and why that is problematic. It's not that one understanding is better than the other - but due to factors of structural racism, the same individuals who have been utilizing these healing practices for thousands of years are now being barred from the current conversations.
\end{abstract}

There are multiple sections to this paper. First, there is an extensive history section that outlines both ancient history, as well as modern history starting in the 1940s and moving through to the present day. Then, to gain insight into our recent scientific understanding, I shall outline 
the research behind why these substances are coming back into current conversations about healing. I will then make a case for the convergence of Indigenous knowledge and science, ending with a request to the scientific community to be more aware of the role BIPOC communities have in this renaissance - and to be aware that they are not being included as they rightfully should. By not including Indigenous voices and knowledge, we lose the thousands of years of experience and insight into the benefits these powerful substances can have, as well as possible risks and how best to avoid them. 


\section{Ancient History}

The history of psychedelics goes much further back in time and is deeper and more complex than many of those in the Western world might initially acknowledge (El-Seedi et al., 2005), (Miller et al., 2019), (Rätsch, 2005), (Stamets, 1996). In this section I shall be outlining the ancient human history of three important plant medicines: psilocybin, peyote/mescaline, and Ayahuasca, as they are some of the most frequently documented substances from human history. I shall briefly discuss why each of these "entheogens" were so important to these peoples from a historical sociocultural standpoint. For clarity, entheogens can be described as any psychedelic or psychoactive drug that is taken for the express purpose of spiritual or religious practice (Ruck, et al., 1979). All three psychedelics referenced in the ancient history section of this paper are considered entheogens, as the Indigenous people that used them did so for spiritual reasons. I will then move on to more modern history, starting with the discovery of lysergic acid diethylamide - otherwise known as LSD. I will discuss the use and importance of LSD throughout the 1960s and 70s, and at the end of the movement related to U.S. President Richard Nixon and the "War on Drugs." After that we will swing back around to the present, and discuss the current psychedelic renaissance.

The purpose of this extensive history section is to show that psychedelic substances are important to humankind, and have been important for an extremely long time. They are very long-standing in our history, and have provided humans with a tremendous amount of information about ourselves and the world (Rätsch, 2005). Beyond that, as we will see in later sections, they may have significant roles in providing mental and physical health benefits benefits similar to what we see reported in mindfulness practitioners (Frecska et al., 2016), (Simon \& Engström, 2015). I will also briefly discuss what are known as "diseases of 
civilization" (Bynum \& Porter, 2006), and how psychedelics could help combat these ailments (Frecska et al., 2016). There will also be important acknowledgements of the current Western take-over of the psychedelic movement, and how that could be harmful to the Indigenous groups that were first to utilize psychedelics (George, et. al, 2020). My aim is to make the case that the psychedelic renaissance is important, and should be bolstered (safely), as well as ensuring that BIPOC individuals with psychedelic history and meaningful experience do not get cut from the discussion.

\section{Psilocybin}

Perhaps one of the best-known psychedelics is the fungi-sourced psilocybin - more commonly known as "magic mushrooms." It turns out there are reasons it is very well known: to start, these mushrooms grow in every single continent except for Antarctica. They are incredibly widespread and normal to find growing just about anywhere mushrooms grow - the most common areas being wetter, more tropical locations. This is according to a review of the worldwide distribution of psychoactive mushrooms (including but not limited to psilocybin containing specimens) conducted in 2000 by Gaston Guzman, et. al., which recorded not only the number of distinct species of hallucinogenic mushrooms, but also catalogued where they grow. There are over 200 species of Basidiomycota mushrooms that contain psilocybin, the largest genera out of eleven being Psilocybe, with over 116 species (Guzman et al., 2000). The bulk of these grow in Mexico (with 53 separate species being found), but are also located in the Northern Americas, Europe, Asia, Africa, and Australia (and surrounding islands). This means that people all over the world have had access to hallucinogenic mushrooms, psilocybin containing or otherwise such in the case of the Amanita muscaria mushroom, which was an important entheogen of the Indigenous people of Siberia (Nyberg, 1992). 
This brings me to my next point: these mushrooms have been making incredible impacts on the people who consume them for thousands of years. One of the first instances in ancient human history that we can tangibly see (not to say that they didn't have importance before then), are the Mayan "mushroom stones" of Guatemala - carbon dated to 1000 BCE. These statues were excavated from Mayan ruins and were a clear sign of how revered these mushrooms were to the people (Borhegyi, 1961). Beyond that, the Aztec even had a word for a species of Psilocybe mushrooms that they called teonanacatl, otherwise known as "God's Flesh" (Stamets, 1996). They considered the mushrooms to be holy sacraments, and had several ceremonies and rituals tied to consuming them. These ceremonies were noted by the Spanish invaders who came to conquer Mesoamerica in the $16^{\text {th }}$ century, but then were promptly forbidden by said invaders, in the name of squashing anything they considered to be "satanic" or "pagan idolatry." (Stamets, 1996). In fact, they tried their best to completely suppress not only the rituals, but anything related to reverence for the mushroom, included the aforementioned Mayan statues. The deep, rich and complex history of the mushroom to these people was nearly wiped out entirely (Stamets, 1996). This is a shame, and also quite interesting to me, considering that the same world that effectively wiped out the already established power of psychedelics is the same world that now can't get enough of it. This will be touched on later in this literature review, however. For now, the point is that these psychedelics are important to people. This is clear before we even gain an understanding of the science of why they might be so important.

\section{Peyote/Mescaline}

This next substance is less ubiquitous than psilocybin but undoubtedly just as important to the peoples who have consumed it for thousands of years. Mescaline is a psychedelic compound that is extracted, usually through means of cooking, from the Peyote cactus, the San 
Pedro cactus, and a couple less well-known cacti. These cacti and the resulting extracted compound have been used for at least 5,700 years by Native American populations in precolonized Mexico, part of which is now known as Texas. This data was gathered through carbon dating mescaline "buttons" that were found with other significant cultural material (El-Seedi et al., 2005). Similar to psilocybin, this psychedelic protoalkaloid ${ }^{1}$ holds significant religious and cultural importance to the groups who used it in ritual practice.

One of the first historical documentations of the use of mescaline was recorded by Spanish colonizers around the late 1600's and early 1700's (Jones, 2007). This way of life continued to be up-rooted during the 1800's, as tribes were forced away from their homelands into new, unaccommodating conditions - a place where mescaline containing cacti did not grow. Through this restriction came a retaliation, however; peyote was slowly being re-introduced into their lives via horseback trading, and peyote rituals went from unnamed but commonly practiced rituals to the creation of an entire church based around the cactus. It is unclear exactly which tribe established the NAC (Native American Church), but the church's main goal was to protect and strengthen the Native American right to perform peyote rituals (Jones, 2007).

The NAC served as a way to band together tribes and individuals under symbology and meaning - but beyond that, peyote rituals served to provide a "needs-based solution to psychological problems Native Americans were encountering in the newly enforced reservation system" (Jones, 2007). In this case, the consciousness-expanding power of mescaline would help NAC members to "heal physical, mental, and spiritual imbalances within themselves and among their social relations, helping to assuage the effects of the needs-denying arrangements of the

\footnotetext{
${ }^{1}$ A protoalkaloid is a type of alkaloid (a naturally occurring organic compound produced by living organisms including plants, bacteria, fungi and animals) originating from amino acids. Many protoalkaloids are also psychoactive in nature (Aniszewski, 2015).
} 
reservation system" (Jones, 2007). The point here is that despite any attempts to quell or suppress the use of psychedelics, those who are able to harness its power for healing will fight for their right to do so, regardless of how difficult that fight may be. This again points to the importance of psychedelic compounds to these individuals.

\section{Ayahuasca}

Ayahuasca, otherwise known as the "vine of the soul" in the Quechua language (Luna, 2011) is a brew made by the Indigenous peoples who reside in the Amazon basin. The primary psychoactive compound contained within the brew is $N, N$-Dimethyltryptamine (more commonly known as DMT) which is extracted from the Psychotria viridis shrub (or other DMT containing plants) through a process of boiling (Riba et al., 2003). This preparation is more than simply DMT, however. What sets Ayahuasca apart from other DMT preparations is the inclusion of the Banisteriopsis caapi vine. This vine, when boiled, releases a monoamine oxidase inhibitor (MAOI), a type of psychoactive compound that is quite well known in the United States and around the world for its anti-depressant effects. These specific alkaloids contained within the vine are known as harmine, harmaline, and tetrahydroharmine (Riba et al., 2003). These alkaloids prevent deamination of DMT in the gut when combined, meaning that the DMT does not break down as easily and this leads to more exposure, with stronger and longer lasting effects (Ruffell et al., 2020).

As with psilocybin and mescaline, it is impossible to know the true ancient history of its use, although it is speculated to reach back millennia. However, there is physical evidence of the use of Ayahuasca dating back to 1,000 years ago. This evidence was extracted and carbon-dated from what was deemed a "ritual bundle," a fox-snout pouch carefully stitched together, implying the importance of it as an entheogen to the Indigenous folks who partook (Miller et al., 2019). 
Aside from physical evidence, we also have anthropological evidence stemming from Spanish and Portuguese colonizers who demonized and attempted to fully eradicate Ayahuasca rituals from Indigenous South America (Soibelman, 1995). We can start to notice a theme here:

Indigenous cultures discover and have significant use for these entheogens which they utilize for thousands of years, until the Western world attempts to abolish anything they consider to be "satanic" in the name of Christian theology (Stamets, 1996). This is important to realize as the psychedelic renaissance continues to unfold within the Western world - these substances have been around for much, much longer than we may give credit for.

\section{Modern Western History of Psychedelics}

Just as it is important to recognize the ancient world history of psychedelics, we must also acknowledge the more recent and scientifically based Western understanding of these fascinating compounds. I would like to note that neither approach is necessarily more valid, and that both perspectives may contribute to a richer and more insightful understanding of the meaning and significance of these substances to humankind.

\section{Albert Hoffman's Discovery of LSD}

An appropriate place to start when considering the scientific history of psychedelics (mainly due to the historical significance and popularity of this event) is the discovery of an important chemical compound - one that would change the life of its discoverer and many people after him: that being Albert Hoffman's discovery of Lysergic Acid Diethylamide, otherwise known as LSD. As stated in Hoffman's 1996 speech LSD: Completely Personal, the initial synthesis happened on November $16^{\text {th }}, 1938$. Hoffman was experimenting with ergot alkaloids to “obtain a novel, improved circulatory stimulant" (Hoffman, 1996). At first, he was unsure of its 
efficacy for much of anything, and left the chemical synthesis alone for the next five years, until one day he had the urge to experiment with the substance again. He recounts that his first exposure was accidental, and so on April $19^{\text {th }}, 1943$, he purposely dosed himself and went on what he described as a "horror trip." While that sounds unpleasant at best, that didn't stop him from realizing LSD's potential and he continued to study the chemical. (April $19^{\text {th }}$ is now affectionately known for many who partake as "Bicycle Day," in reference to Hoffman's ride home while under the influence.)

He later describes his "horror trip" as frightening at points, but also enlightening (Hoffman, 1996). This leads to the modern idea that there is no such thing as a "bad trip," but rather challenging trips that can be learned from. Michael Pollan, a modern (and quite popular) psychedelic researcher and writer, and Bridget Huber, his research assistant, write about their findings of a Johns Hopkins survey taken on the challenging experiences people had under the influence of psilocybin: “...interestingly enough, despite these negative experiences, many of the survey respondents still found even these bad trips to be meaningful and spiritually important. For 34 percent of participants, their most challenging trip on psilocybin was ranked among the top five most meaningful experiences of their life. And 31 percent said it was among the top five most spiritually significant experiences of their life. Eighty-four percent of the respondents said they had benefited from the challenging parts of their trip and 46 percent said they would repeat that session if they could, despite the challenges" (Huber \& Pollan, 2020).

So being that Albert Hoffman was a Swiss scientist, how did LSD make its way over to the United States? Well, to start, the Swiss laboratory that held its discovery was intrigued by LSD's possible usefulness, and thus became a commercially available medication (under the name Delysid) for a variety of different psychiatric uses in 1947, following the 1943 patent of the 
substance (Hoffman \& Stoll, 1943). Then in 1949, the same laboratory that assigned the patent in Switzerland brought the US government to the attention of LSD citing possible usefulness in clinical applications, that laboratory being Sandoz Laboratories (Pollan, 2019). This introduction launched a decades long battle for and against LSD on all sides (civilian, government, and scientific.) Even Time magazine published six separate reports about the positive benefits of LSD, from 1954 to 1959 (Shafer, 2010).

There is a sizeable amount of LSD history contained within the decades of the 1950 and 1960s, and so I will do my best to keep the information concise. Essentially, throughout the 1950's, there were a growing number of researchers looking at the possible uses of LSD, starting with a method of producing "model psychosis," through which mental illness could be studied. This is indicative of the approach towards psychology at the time, which was primarily focused on the "illness" side of mental illness (Langlitz, 2006). An important name throughout all this is Sidney Cohen, a leading research authority on LSD in the 1950's. After having taken the substance for the first time on October $12^{\text {th }}, 1955$, he recounts his experience as being surprisingly positive, considering the current mental illness rhetoric that was being pushed by fellow researchers, as we can see here:

“[Cohen] expected to feel catatonic or paranoid, but instead, he wrote, 'I was taken by surprise. This was no confused, disoriented delirium, but something quite different.' His subsequent report described feeling an elevated peacefulness, as if 'the problems and strivings, the worries and frustrations of everyday life vanished; in their place was a majestic, sunlit, heavenly inner quietude... I seemed to have finally arrived at the contemplation of eternal truth"” (Novak, 1997). After this personal discovery he teamed up with another important name in psychedelic history: Aldous Huxley. Together with Betty Eisner, the team explored whether or 
not LSD could be helpful to facilitate psychotherapy, address alcoholism and enhance creativity (Novak, 1997).

Studies continued on into the 60s and even the mid-70's as LSD grew in popularity, both among the masses and among academic researchers. This includes Richard Alpert, better known as Ram Dass, who was also experimented on using LSD during MK Ultra²; and Timothy Leary, a psychology professor at Harvard, who is known for his activism in making LSD publicly known and revered among counterculture groups at the time. The two worked together to perform dubious (by today's standards) scientific research at Harvard, until they were both kicked from the school altogether, fueling Leary's activism. This advocacy, however, may have backfired - as even Albert Hoffman states in his book LSD: My Problem Child:

"The evolution of LSD from remedy to inebriating drug was, however, primarily promoted by the activities of Dr. Timothy Leary and Dr. Richard Alpert of Harvard University" (Hoffman, 2009).

This brings me to an important aside. These substances are powerful - and cannot and should not be taken or given out with negligence. With great power comes great responsibility and I'm afraid that, at least in their years of research, Timothy Leary and Richard Alpert did not do their due diligence to keep people safe and to keep their research sane (Hoffman, 2009). According to Hoffman's firsthand accounts of his 1970s meetings with Dr. Leary, the LSD apostle (as he was known at the time) had slipped away from pure scientific method and into his

\footnotetext{
${ }^{2}$ MK Ultra was a US governmental CIA program that wrongfully and destructively experimented with LSD on vulnerable subject groups - including mentally ill patients, prisoners, drug addicts and sex workers in the 1950's. The group claims this was necessary in order to determine if LSD was effective as a "truth serum" they could use on prisoners of war. All of this is considered extremely unethical by today's research standards (Linville, 2016).
} 
own "experimentation," hosting LSD parties that were far removed from their original scientific purpose (Hoffman, 2009). Hoffman describes him as a passionate person who is very sure of his mission - so much so that he had lost sight or frequently overlooked the potential downfalls or risks to psychedelic therapy (Hoffman, 2009). This is part of the reason we must move forward into further psychedelic research with the utmost care and consideration. Because of institutional review boards (IRBs), which engage community members to help evaluate research proposals before approval and require informed consent, research is done more ethically today. There is no reason to blindly fear these substances - it just pays to be mindful.

\section{The War on Drugs}

Due to in part of the unfortunate mishandling of these powerful substances, in the year 1966 LSD was declared a Schedule 1 substance, the most illegal a drug could be (Affairs, 1999). Richard Nixon, elected as the President of the United States in 1969, is perhaps best known for his involvement in the Vietnam War, his Watergate scandal that lost him his presidency and credibility and for starting the global campaign known as the "War on Drugs," that continues to this day - despite the controversy that surrounds it (Gonzalez et al., 2019).

While a "War on Drugs" may perhaps at first sound like a helpful thing which could prevent addiction and general harm to users, there are many underlying problems at play here. Perhaps most importantly, the war on drugs could be argued as not a war on drugs, but a war on people that the government deems less desirable. This included those struggling with drug use disorders, who are themselves generally viewed by the Drug Enforcement Agency (DEA) and other governmental agencies as dangerous criminals, rather than people with mental illness who need help, thanks to the stigma that the war on drugs helps perpetuate (Buchanan \& Young, 2000) - but notably this also includes and disproportionally affects POC, particularly low- 
income Black and Latinx communities (Rosino \& Hughey, 2018). This is an element of a much larger, systemic problem that we face in our current culture, that being structural racism. Before we can recognize the role of structural racism in the War on Drugs, we must first gain an understanding of what structural racism is.

From a 2004 presentation written by Keith Lawrence and Terry Keleher for a Race and Public Policy Conference: "Structural Racism in the U.S. is the normalization and legitimization of an array of dynamics - historical, cultural, institutional and interpersonal - that routinely advantage Whites while producing cumulative and chronic adverse outcomes for people of color. It is a system of hierarchy and inequity, primarily characterized by White supremacy - the preferential treatment, privilege and power for White people at the expense of Black, Latino, Asian, Pacific Islander, Native American, Arab and other racially oppressed people" (Lawrence $\&$ Keleher, 2004). Structural racism is embedded into the very fabric of society, and affects BIPOC (Black Indigenous People of Color) on nearly all levels - but particularly when it comes to health inequities (Bailey et al., 2021). Structural racism is not just about prejudices held by individuals, but goes beyond that into the production and reproduction of laws, rules, and practices that are enforced and upheld by governmental institutions, within economic systems and in social and cultural norms (Bailey et al., 2021), (Bailey et al., 2017), (Rothstein, 2017).

In a 2018 study of the War on Drugs and its relation to structural racism, authors Michael L. Rosino and Matthew W. Hughey have taken 30 years' worth of news content relating to the topic and from there proposed a framework that "considers the history of racially motivated laws and practices and moral panics among Whites who have blamed drug-related social problems and crime on marginalized racial groups" (Rosino \& Hughey, 2018). They argue that drug law enforcement is unnecessarily violent, forceful, and usually ends in imprisonment - which hits 
marginalized groups particularly hard and lends itself to perpetuating structural racism (Rosino \& Hughey, 2018). They outline a growing body of research that examines the "racialization and expansion of the American justice system and its social ramifications" (Rosino \& Hughey, 2018). Essentially, their findings point to racial oppression in the United States related to the racialization and militarization of drug enforcement policies. Marginalized communities are targeted due to the fear around racial groups as being threatening or dangerous, even though Whites tend to engage in more drug offenses than their BIPOC counterparts:

"Empirical evidence overwhelmingly demonstrates Blacks are targeted for arrest and punishment in disproportion to their actions relative to Whites. However, many politicians, legal authorities, members of the public, and even criminologists fail to identify racial prejudice and discrimination as systemic factors in criminal justice” (Rosino \& Hughey, 2018).

As is evident from the article, the War on Drugs has had devastating effects on the exact communities that need to be protected. I feel that it is of the utmost importance that one of the goals of the modern-day Psychedelic Renaissance should be to recognize these elements of the fight against the War on Drugs, considering the White-dominant medical framework that resides at the forefront of the renaissance. Indigenous communities have always utilized psychedelics in very deeply meaningful ways, so I believe that we must strive to include BIPOC individuals in our conversations.

\section{The Psychedelic Renaissance}

It appears that within the past 10-20 years, psychedelics are once again gaining ground in the psychological and psychiatric world as powerful tools of healing (Giffort, 2020), (Sessa, 2017). In this section I discuss relationships between brain function and structure, including the 
connection between depression, anxiety, and addiction and what is known as the "Default Mode Network" of the brain. Psychedelics have the ability, under proper conditions and care, to help assuage the effects of a malfunctioning Default Mode Network that contributes to all of these mental ailments. These links shall be made evident through psychological studies, which are described below.

\section{The Science Behind Psychedelics}

\section{A General Overview of the Default Mode Network}

In order to understand how psychedelics could possibly benefit someone suffering from symptoms of depression, anxiety and/or drug use disorders, we must first begin to understand why we have these symptoms in the first place. Naturally, these mental ailments are incredibly complicated, and so for the purpose of this paper, we shall be focusing on a very specific function of the brain in order to keep it concise. This function, and the network of brain regions involved, is known as the Default Mode Network (hereby referred to as DMN). Essentially, the $\mathrm{DMN}$ is a collection of areas within the cerebral cortex that are responsible for resting-state activity within the brain. Whenever you are not focused on an "attention-demanding, goaldirected" task, i.e., you are in a "resting" brain state (often described in research articles as the "control" condition); the DMN is active, and is responsible for "self-referential processing and mind-wandering" (Raichle, 2015). This refers to both self-evaluation, as well as perceived evaluation from others (otherwise known as social evaluations). This can clearly be an active "resting" state. If you have ever wondered why you cannot seem to shut your brain off at 2 am, wanting to sleep but instead thinking about that one time in $8^{\text {th }}$ grade where that embarrassing thing happened - you can thank your DMN for that. 
Beyond the classical understanding of the DMN being an 'intrinsic system' - meaning that it's an internally oriented process of the brain responsible for self-reference, daydreaming, and thoughts about the past and future - the DMN may also be a 'sense-making' network (Yeshurun et al., 2021). The two functions seem to work in tandem with one another: "...the $\mathrm{DMN}$ is an active and dynamic 'sense-making' network that integrates incoming extrinsic information with prior intrinsic information to form rich, context-dependent models of situations as they unfold over time" (Yeshurun et al., 2021). It is still true that the DMN is active during the brain's resting state, but it has been suggested that "the response of the DMN is locked to external stimuli, especially during social interactions, and thus can be considered extrinsic... the DMN is at the nexus of the interaction between the external and internal worlds" (Yeshurun et al., 2021).

There is evidence that sufferers of depression, anxiety and substance use disorders all have altered DMN functionality (Coutinho et al., 2015), (Sheline et al., 2009), (Zhang \& Volkow, 2019). The exact type of disfunction varies between ailments, but it has been shown that all three alter the regular resting state activities of the brain. In depression, it has been shown that sufferers fail to normally down-regulate DMN activity, as well as having heightened responses to stimulus-induced negativity (Sheline et al., 2009). This means that these individuals are more receptive to negative evaluations of their world, and have a harder time shutting down those evaluations (Sheline et al., 2009). As for anxiety, the results are fairly similar. For both depression and anxiety, the same areas and functions have been shown to be altered. Specifically, the functional connectivity within the anterior portions of the DMN which are related to self-referential and emotional processes were found to be positively correlated with those suffering from anxiety and depression (Coutinho et al., 2015). However, the posterior areas 
related to episodic memory and perceptual processing were found to be negatively correlated (Coutinho et al., 2015). In more simplified terms, individuals suffering from depression and anxiety are spending more time thinking about and ruminating on social evaluations and emotions, and have a harder time perceiving and remembering events "correctly" (Coutinho et al., 2015).

As for substance use disorders (SUDs), it has been shown that the DMN is again not functioning normally, and this dysfunction is associated with cravings and relapse (Zhang \& Volkow, 2019). Specifically, the resting functional connectivity of the anterior DMN (which as we learned above, is related to self-referential and emotional processes) decreases, which leads to poor emotional regulation (relapse) and less care towards the self, allowing one to give in to cravings without thinking of the negative consequences that action may have on the self (Zhang \& Volkow, 2019). On top of that, the DMN as a whole is overly active during withdrawal and when in a resting state, leading addicted individuals to ruminate about taking the substances they are currently withdrawing from (Zhang \& Volkow, 2019). We also see disrupted connectivity between the DMN and cortical regions that deal with executive functioning and memory, making it difficult for the addicted individual to fully perceive and understand the effects their substance use disorder is having (Zhang \& Volkow, 2019). All of this together leaves these individuals in a battle against their own brain and chemistry.

\section{Psychedelics and Meditation as Possible Solutions}

Now that we know the role the DMN plays in these three afflictions, we can start to look into methods that help reduce dysfunction in the DMN. Interestingly, both the influence of psychedelics on the brain, as well as meditation and other mindfulness techniques can have positive therapeutic results in treating mood disorders, even for treatment resistant individuals 
(Kelly et al., 2019), (Kenny \& Williams, 2007). First, let's focus on psychedelics. According to a 2018 literature review published on the effects of psychedelics (psilocybin, lysergic acid diethylamide, ketamine, and ayahuasca) on the DMN, there are significant alterations within the function of the DMN that may mark the efficacy of psychedelic-assisted psychotherapy. Fascinatingly, the DMN has been shown to function in the exact opposite way than it does in mood disorders when sufferers are under the influence of psychedelics (Ruban \& Kołodziej, 2018). To clarify, the DMN is found to have increased activity of main nodes, as well as abnormal functional connectivity when afflicted by mood disorders. Under the influence of psychedelics, however, the DMN activity is leveled and positive coupling between main nodes is reduced. This points to a potential functional mechanism for psychedelics' effectiveness in combatting mood disorders related to the DMN (Ruban \& Kolodziej, 2018).

A study conducted in 2016 by Carhart-Harris at the Imperial College London has shown that an amazing "sixty-seven percent of participants with treatment resistant depression had significantly reduced depression symptoms at 1 week, with $40 \%$ of participants showing a sustained response at 3 months post-dose" (Kelly et al., 2019). This is an important finding, considering that treatment resistant depression is just that: treatment resistant. From my own experience talking with people experiencing treatment resistant depression, it can be outright debilitating - so these findings are hugely significant for this population. In fact, the Food and Drug administration granted psilocybin 'breakthrough therapy' status in 2018, and in 2019 and 2020 respectively, Colorado and Oregon decriminalized the possession of psilocybin (Ordinance 301, 2019), (Measure 109, 2021). Once rules are established, permit holders can conduct psilocybin-assisted therapy within specified centers of healing. 
Slowly but surely the Western world, driven by ethically bound science is catching on to the knowledge that Indigenous people have understood for thousands of years. Another ancient knowledge that is being "rediscovered," within the context of healing mood disorders such as depression and anxiety, are meditation and mindfulness techniques. Interestingly, mindfulness evokes similar changes in the brain as psychedelics, specifically within the functionality of the DMN. Since we can already start to look at specific dysfunctions of the DMN as a biomarker for diagnosis, we can also start to look at changes within that functionality during the course of treatment, as a biomarker for the efficacy of said treatment (Simon \& Engström, 2015). This was shown to be accurate with psychedelic-assisted therapy (Ruban \& Kołodziej, 2018); although more research is certainly required in order to make any conclusive statements. Specifically for the case of meditation, modulation of the DMN is the highest predictor of efficacy for treatment. In other words, the practice of meditation helps a person suffering from rumination quell their overactive thought processes (Simon \& Engström, 2015).

Researchers have been looking into ways to combine psychedelic-assisted psychotherapy and mindfulness techniques, considering the potential that both treatments have, as well as the similarities between how they impact the brain. This research is quite new, and as such must be tested, as we can see in a 2019 study looking at psilocybin-assisted mindfulness training conducted by Smigielski, et al. They set up a randomized, placebo-controlled, double-blind study in which 38 participants were given a single dose of psilocybin before a 5-day mindfulness retreat. (As an aside, an interesting phenomenon about psychedelics is that they tend to provide long-lasting benefits (Nichols et al., 2016), and so one dose over the span of 5 days can certainly be enough to maintain effects.) The researchers started with an fMRI to gain a base level 
understanding of DMN functionality within the participants, and then scanned them again during resting-state activity as well as during two forms of mindfulness training.

It was found that the psilocybin had a synergistic effect with the mindfulness therapy sessions. Specifically, the regions of the DMN that mediate a sense of self were found to be decoupled during the psilocybin-assisted mindfulness sessions, those regions being the medial prefrontal and posterior cingulate cortices - areas which both psilocybin and meditation affect (Smigielski et al., 2019). This decoupling from both psilocybin and mediation is associated with a subjective ego dissolution effect, which in turn predicted "positive changes in psycho-social functioning of participants 4 months later" (Smigielski et al., 2019). As it turns out, the common psychedelic moniker of "ego death" can indeed be tracked in the brain, on top of being able to physically track the positive effects that an experience of ego death may have.

\section{Diseases of Civilization}

Going along with our theme of Western, science-based knowledge and its modern convergence with ancient or Indigenous knowledge, I would like to briefly discuss what are known as "diseases of civilization" - and then how psychedelics may play a role in helping us overcome these diseases. Technically it can be said that all diseases that affect any civilization at any period of time can be considered diseases of civilization. However, there are specific diseases linked to modern-day Western life, such as heart disease and obesity through a high sugar, high fat diet or unequal access to healthy food or opportunities for exercise and preventative care (Bynum \& Porter, 2006). In fact, it is often those who have inadequate access

\footnotetext{
${ }^{3}$ As described by Timothy Leary in "The Psychedelic Experience," a psychedelic "ego death" is the experience of a "complete transcendence" of the self, in which a sort of death and rebirth of the self can occur (Leary et al., 1966).
} 
to healthy living (those living under the poverty line, full-time minimum wage workers with families to feed and racially discriminated groups) that suffer the most from diseases of civilization, due to environmental aspects of poor working conditions and stress - among other factors (Bynum \& Porter, 2006).

These diseases go beyond the physical, as one could imagine, and into the psychological. This includes depression, anxiety, ADHD, drug use disorders and more. Combatting these afflictions under the lens of civilization being the root cause seems like a practice in hopelessness, considering the overarching structures of capitalism that keep us firmly rooted in this type of civilization (Matthews, 2019), (Olivier, 2015), (Prins et al., 2015). There may be hope, however, contained within a specific ancient knowledge that was discussed at the beginning of this paper - that knowledge being the ritual use of Ayahuasca. This is according to a literature review conducted in 2016 by Frecska et al., in which the researchers compiled information pertaining to what Ayahuasca is, what it does to the brain and body, and whether or not these effects are therapeutically and possibly physically beneficial. Specifically, they studied its effects against diseases of civilization. For the purpose of this paper, I will focus on the psychological side, but there is also significant evidence pointing towards a possible role of DMT in tissue protection and neuro-regeneration, as well as in protection against possible Sig1R receptor related diseases such as cancer and Alzheimer's disease (Frecska et al., 2016).

A common physiological thread between most diseases of civilization (physical or otherwise) is chronic Low Oxidative Inflammation (LGI). LGI is caused by constant psychological stress (such as poor working conditions with little to no access to therapy and time off), environmental pollution, and even smoking behaviors. LGI is implicated in a number of degenerative diseases, such as autoimmune diseases, cancer, Alzheimer's, and most notably for the case of this paper, 
major depression (Aseervatham et al., 2013), (Frecska et al., 2016). Without getting into the complicated neurobiology of it all, it's important to note that Ayahuasca acts on the Sig-1R receptor in a way that helps alleviate the degenerative impacts of LGI on cellular processes. In other words, LGI causes cellular stress, which over time can have severe effects on the brain and body. Ayahuasca can potentially act as a broad-spectrum remedy, "which hits the dead center of the discussed vicious circle of the malfunctioning molecular web involved in oxidative stress" (Hayashi, 2015), (Frecska et al., 2016).

There is evidence that Ayahuasca may also help those suffering from substance use disorders due to its direct and indirect effects on both dopaminergic and serotonergic systems: “...the resolution of addiction through ayahuasca's therapeutic potentials may act on four levels: (1) reducing brain DA (dopamine) level in the MDP (mesolimbic dopamine pathways) through effects on the 5-HT (serotonin) receptors, which in turn (2) interferes with the synaptic plasticity. This neurochemical mechanism is supported by (3) psychological insights and processing of repressed traumas, enhancing decision making capabilities, which allows the person to (4) examine first person transcendental experiences" (Frecska et al., 2016). Let's break down what this particular researcher is proposing; thanks to certain mechanisms that Ayahuasca exerts on the brain, this powerful psychedelic might allow an individual suffering from substance abuse disorders to gain new insight into the root cause of their addiction (trauma) and hopefully, with support, overcome it.

As for other mental afflictions, Ayahuasca works similarly, reportedly bringing forth deeply buried subconscious material in a way that sometimes helps the individual learn about themselves via illumination of perspectives previously unknown and unseen. This helps the individual gain insight into maladaptive behavior or emotional and cognitive patterns that are 
otherwise ingrained, and difficult to shake (Frecska, et al., 2016). Ayahuasca helps to encourage the individual to acknowledge their ingrained emotional and cognitive patterns - and thus offers the understanding needed to change maladaptive behaviors and thinking (Loizaga-Velder \& Verres, 2014), (Frecska, et al., 2016).

Perhaps Ayahuasca could help heal the ailments that a modern day Western life can produce. However, there are many considerations that the scientific world must investigate if we go forward with this type of therapy. We must recognize that the current frameworks of psychedelic psychological studies and professions are White-dominant (Buchanan, 2020). Not only that, but the current models and theories for treatment are framed within the White experience, in that there is little to no understanding of the needs and worldviews of BIPOC individuals - and thus is generally unhelpful to these populations. (Buchanan, 2020). We must take extra steps to ensure that low SES and disadvantaged groups, such as BIPOC receive just as much benefit from this type of healing as their White counterparts. This is especially true as the world of Indigenous psychedelic use is increasingly appropriated (Labate \& Conrad, 2019).

\section{Considerations Towards the Future}

\section{The Role and Current Exclusion of BIPOC in Psychedelic Healing}

To recap what we have learned so far: psychedelic healing has been an important part of Indigenous cultures long before Albert Hoffman and the current psychedelic renaissance. That being said, the scientific basis of the Western understanding of psychedelics is necessary to more clearly understand what these substances can do for us, and how to keep individuals needing treatment safe while undergoing psychedelic therapy. Unfortunately, Indigenous peoples are being left out of this conversation, partly due to the White-dominant medical framework that 
psychology work resides within - considering that the workforce and trainee pipeline are majority White (APA, 2018). Furthermore, BIPOC communities are not receiving the same level of benefit from the psychedelic renaissance as White communities (Buchanan, 2020), in that over $80 \%$ of participants in trials are White, with less than $3 \%$ being Black (Michaels et al., 2018). So, what can the individuals with the power of privilege and academia on their side do to ensure that everyone receives the same treatment? The first step is to listen to BIPOC people and to learn. As such, let's take a look at an article written by George, et. al, in 2020 about "The psychedelic renaissance and the limitations of a White-dominant medical framework: A call for indigenous and ethnic minority inclusion” (George et al., 2020).

Essentially, there are a few cultural and social forces that have led to the suppression and even silencing of Indigenous and minority voices within the scientific psychedelic community. It started in the 1950's and 1960's with the appropriation of psychedelics by the White "hippies" of the time, who specifically wanted to transform themselves with the drugs, music, and spiritualities of other populations (George et al., 2020), (Saldanha, 2007). Despite their fascination with other cultures, hippies failed to understand the damage they were doing to the exact culture they wanted to appropriate, via the perpetuation of negative stereotypes (LemkeSantangelo, 2010). While hippies were trying to transform themselves through transcendental means, Black and Indigenous populations were being viewed as dangerous, "druggie" criminals for wanting to do the same or just for being themselves (Williams, Gooden, \& Davis, 2012).

More recently, we have mass incarceration of BIPOC individuals and communities that essentially perpetuate a new type of classist segregation, known as the "New Jim Crow" (George et al., 2020). BIPOC are more likely to be arrested and charged much more harshly (with longer sentences) for drug crimes than their White counterparts - despite similar rates of drug usage 
(Forman, 2012). With the fear of life-long imprisonment (or the effects of short term incarceration on their lives moving forward, such as decreased access to housing and jobs) looming over their shoulders, BIPOC communities can't even begin to think of psychedelic treatment as viable options (George et al., 2020). Furthermore, problems within BIPOC communities are not seen as problems until the same issues start to affect White communities and as such are not recognized until the problems are deeply set (George et al., 2020). Beyond that, with a history of understandable mistrust towards medical treatments, thanks to horrific instances like the Tuskegee Syphilis experiments, it is no wonder that the benefits of psychedelic therapy are not reaching BIPOC communities (George et al., 2020). There is significant work that needs to be done in recognizing the effects of these traumatic events, and part of that is ensuring that BIPOC are part of the conversation about psychedelic healing going forwards.

\section{Conclusion}

My aim is to make the case that the psychedelic renaissance is important and should be bolstered (within the safest means possible), as well as ensuring that BIPOC individuals with psychedelic history and meaningful experience do not get cut from the discussion. There is scientific evidence that psychedelic therapy could greatly benefit society going forward. But we must be aware of and include the role of Indigenous knowledge in this shift, considering the great amount of history these communities have with these substances. It's also important to know that right now the benefits of the psychedelic renaissance are not reaching BIPOC individuals and communities thanks to structural racism and a White-dominated psychological workforce, among other factors. My hope for this literature review is to bring awareness to the current gap in accessibility for this therapy, and to demonstrate why we must push for change. 


\section{References}

Affairs, D. E. A. P. (1999). DEA - Publications - LSD in the US - The Drug. https://web.archive.org/web/19990427145322/http://www.usdoj.gov/dea/pubs/lsd/lsd4.htm.

American Psychological Association. (2018). Demographics of the U.S. psychology workforce: Findings from the 2007-16 American Community Survey. Washington, DC: Author.

Aniszewski, T. (2015). Definition, Typology and Occurrence of Alkaloids. In Alkaloids - secrets of life: alkaloid chemistry, biological significance, applications and ecological role (pp. 611). Elsevier.

Aseervatham, G. S., Sivasudha, T., Jeyadevi, R., \& Arul Ananth, D. (2013). Environmental factors and unhealthy lifestyle influence oxidative stress in humans - an overview. Environmental Science and Pollution Research, 20(7), 4356-4369. https://doi.org/10.1007/s11356-013-1748-0

Bailey, Z. D., Feldman, J. M., \& Bassett, M. T. (2021). How Structural Racism Works - Racist Policies as a Root Cause of U.S. Racial Health Inequities. New England Journal of Medicine, 384(8), 768-773. https://doi.org/10.1056/nejmms2025396

Bailey, Z. D., Krieger, N., Agénor, M., Graves, J., Linos, N., \& Bassett, M. T. (2017). Structural racism and health inequities in the USA: evidence and interventions. The Lancet, 389(10077), 1453-1463. https://doi.org/10.1016/s0140-6736(17)30569-x

Borhegyi, S. F. (1961). Miniature Mushroom Stones from Guatemala. American Antiquity, 26(4), 498-504. https://doi.org/10.2307/278737

Buchanan, J., \& Young, L. (2000). The War on Drugs - a war on drug users? Drugs: Education, Prevention and Policy, 7(4), 409-422. https://doi.org/10.1080/713660130

Bynum, W. F., \& Porter, R. (2006). In Companion encyclopedia of the history of medicine (pp. 585-599). Routledge Taylor \& Francis Group.

Coutinho, J. F., Fernandesl, S. V., Soares, J. M., Maia, L., Gonçalves, Ó. F., \& Sampaio, A. (2015). Default mode network dissociation in depressive and anxiety states. Brain Imaging and Behavior, 10(1), 147-157. https://doi.org/10.1007/s11682-015-9375-7

Denver, Colorado, Initiated ORDINANCE 301, psilocybin MUSHROOM Initiative (May 2019). Ballotpedia. (2019).

https://ballotpedia.org/Denver,_Colorado,_Initiated_Ordinance_301,_Psilocybin_Mushroo m_Initiative_(May_2019). 
El-Seedi, H. R., Smet, P. A. G. M., Beck, O., Possnert, G., \& Bruhn, J. G. (2005). Prehistoric peyote use: Alkaloid analysis and radiocarbon dating of archaeological specimens of Lophophora from Texas. Journal of Ethnopharmacology, 101(1-3), 238-242. https://doi.org/10.1016/j.jep.2005.04.022

Forman, J. (2012). Racial critiques of mass incarceration: Beyond the new Jim Crow. New York University Law Review, 87(1), 101-146. Retrieved from https://digitalcommons.law.yale.edu/cgi/viewcontent.cgi?article=4599=fss_papers

Frecska, E., Bokor, P., \& Winkelman, M. (2016). The Therapeutic Potentials of Ayahuasca: Possible Effects against Various Diseases of Civilization. Frontiers in Pharmacology, 7. https://doi.org/10.3389/fphar.2016.00035

George, J. R., Michaels, T. I., Sevelius, J., \& Williams, M. T. (2020). The psychedelic renaissance and the limitations of a White-dominant medical framework: A call for indigenous and ethnic minority inclusion. Journal of Psychedelic Studies, 4(1), 4-15. https://doi.org/10.1556/2054.2019.015

Giffort, D. (2020). Acid revival: the psychedelic renaissance and the quest for medical legitimacy. University of Minnesota Press.

Gonzalez, J. J., McGee, M. P., \& Schultz, D. (2019). Law, Legalization, and the Failed War on Drugs. In Legal marijuana: perspectives on public benefits, risks and policy approaches (pp. 206-208). essay, McFarland \& Company, Inc.

Guzman, G., Allen, J. W., \& Gartz, J. (2000). A Worldwide Geographical Distribution of the Neurotropic Fungi, An Analysis and Discussion. Research Gate.

https://www.researchgate.net/publication/237398624_A_Worldwide_geographical_distrib ution_of_the_Neurotropic_Fungi_an_analysis_and_discussion.

Hayashi, T. (2015). Conversion of psychological stress into cellular stress response: Roles of the sigma-1 receptor in the process. Psychiatry and Clinical Neurosciences, 69(4), 179-191. https://doi.org/10.1111/pcn.12262

Hoffman, A. \& Stoll, A. (1943). d-Lysergic Acid Diethylamide. (Swiss Patent No. 533,264). Sandoz Ltd., Fribourg, Switzerland.

Hoffman, A. (1996). LSD: Completely Personal. Worlds of Consciousness Conference, Heidelberg, Germany. https://maps.org/news-letters/v06n3/06346hof.html

Hofmann, A. (2009). In LSD, my problem child: reflections on sacred drugs, mysticism, and science (p. 29). essay, MAPS, Multidisciplinary Association for Psychedelic Studies.

Huber, B., \& Pollan, M. (2020). What do we know about the risks of psychedelics?: Michael Pollan. Michael Pollan | Michael Pollan writes about the places where nature and culture 
intersect: on our plates, in our farms and gardens, and in the built environment. https://michaelpollan.com/psychedelics-risk-today/.

Jones, P. N. (2007). The Native American Church, Peyote, and Health: Expanding Consciousness for Healing Purposes. Contemporary Justice Review, 10(4), 411-425. https://doi.org/10.1080/10282580701677477

Kelly, J. R., Baker, A., Babiker, M., Burke, L., Brennan, C., \& O’Keane, V. (2019). The psychedelic renaissance: the next trip for psychiatry? Irish Journal of Psychological Medicine, 1-5. https://doi.org/10.1017/ipm.2019.39

Kenny, M. A., \& Williams, J. M. G. (2007). Treatment-resistant depressed patients show a good response to Mindfulness-based Cognitive Therapy. Behaviour Research and Therapy, 45(3), 617-625. https://doi.org/10.1016/j.brat.2006.04.008

Labate, B. C., \& Conrad, M. (2019). The global expansion of ayahuasca through the Internet. In The expanding world Ayahuasca diaspora: appropriation, integration and legislation. essay, Routledge.

Langlitz, N. (2006). Ceci n'est pas une psychose. Toward a Historical Epistemology of Model Psychoses. BioSocieties, 1(2), 159-180. https://doi.org/10.1017/s174585520605023x

Lawrence, K., \& Keleher, T. (2004, November). Structural racism. In Race and Public Policy Conference, Berkeley. Retrieved from http://www.intergroupresources.com/rc/Definitions\%20of\%20Racism.pdf.

Leary, T., Metzner, R., \& Alpert, R. (1966). Psychedelic experience: A manual based on the tibetan book of the dead. CITADEL PR.

Lemke-Santangelo, G. (2010). Daughters of Aquarius: Women of the sixties counterculture. The Sixties, 3(1), 112-115. doi:10.1080/17541328.2010.484968

Linville, Tani M. (2016). "Project MKULTRA and the Search for Mind Control: Clandestine Use of LSD Within the CIA" History Capstone Research Papers. 6. https://digitalcommons.cedarville.edu/history_capstones/6

Loizaga-Velder, A., \& Verres, R. (2014). Therapeutic effects of ritual ayahuasca use in the treatment of substance dependence - qualitative results. Journal of Psychoactive Drugs, 46(1), 63-72. https://doi.org/10.1080/02791072.2013.873157

Luna, L. E. (2011). "Indigenous and mestizo use of ayahuasca: an overview," in The Ethnopharmacology of Ayahuasca, ed. R. G. dos Santos (Kerala: Transworld Research Network), 1-21.

Matthews, D. (2019). Capitalism and Mental Health. Monthly Review, 49-62. https://doi.org/10.14452/mr-070-08-2019-01_5 
Michaels, T. I., Purdon, J., Collins, A., \& Williams, M. T. (2018). Inclusion of people of color in psychedelic-assisted psychotherapy: a review of the literature. BMC Psychiatry, 18(1). https://doi.org/10.1186/s12888-018-1824-6

Miller, M. J., Albarracin-Jordan, J., Moore, C., \& Capriles, J. M. (2019). Chemical evidence for the use of multiple psychotropic plants in a 1,000-year-old ritual bundle from South America. Proceedings of the National Academy of Sciences, 116(23), 11207-11212. https://doi.org/10.1073/pnas.1902174116

Nichols, D. E., Johnson, M. W., \& Nichols, C. D. (2016). Psychedelics as Medicines: An Emerging New Paradigm. Clinical Pharmacology \& Therapeutics, 101(2), 209-219. https://doi.org/10.1002/cpt.557

Novak, S. J. (1997). LSD before Leary: Sidney Cohen's Critique of 1950s Psychedelic Drug Research. Isis, 88(1), 87-110. https://doi.org/10.1086/383628

Olivier, B. (2015). Capitalism and suffering. Psychology in Society, (48), 1-21. https://doi.org/10.17159/2309-8708/2015/n48a1

Oregon psilocybin Services act (Measure 109). Oregon Health Authority : Oregon Psilocybin Services Act (Measure 109) : Prevention and Wellness : State of Oregon. (n.d.). https://www.oregon.gov/oha/PH/PREVENTIONWELLNESS/Pages/psilocybin-servicesact.aspx.

Pollan, M. (2019). History: The Short Wave. In How to change your mind: the new science of psychedelics. essay, Penguin Books.

Prins, S. J., Bates, L. M., Keyes, K. M., \& Muntaner, C. (2015). Anxious? Depressed? You might be suffering from capitalism: contradictory class locations and the prevalence of depression and anxiety in the USA. Sociology of Health \& Illness, 37(8), 1352-1372. https://doi.org/10.1111/1467-9566.12315

Raichle, M. E. (2015). The Brain's Default Mode Network. Annual Review of Neuroscience, 38(1), 433-447. https://doi.org/10.1146/annurev-neuro-071013-014030

Rätsch, C. (2005). The encyclopedia of psychoactive plants: ethnopharmacology and its applications. Park Street Press.

Rothstein R. The color of law: a forgotten history of how our government segregated America. New York: Liveright Publishing, 2017.

Nyberg, H. (1992). Religious use of hallucinogenic fungi: A comparison between Siberian and Mesoamerican cultures. Karstenia, 32(2), 71-80. https://doi.org/10.29203/ka.1992.294 
Riba, J., Valle, M., Urbano, G., Yritia, M., Morte, A., \& Barbanoj, M. J. (2003). Human Pharmacology of Ayahuasca: Subjective and Cardiovascular Effects, Monoamine Metabolite Excretion, and Pharmacokinetics. Journal of Pharmacology and Experimental Therapeutics, 306(1), 73-83. https://doi.org/10.1124/jpet.103.049882

Rosino, M. L., \& Hughey, M. W. (2018). The War on Drugs, Racial Meanings, and Structural Racism: A Holistic and Reproductive Approach. American Journal of Economics and Sociology, 77(3-4), 849-892. https://doi.org/10.1111/ajes.12228

Ruban, A., \& Kołodziej, A. A. (2018). Changes in default-mode network activity and functional connectivity as an indicator of psychedelic-assisted psychotherapy effectiveness.

Neuropsychiatria i Neuropsychologia, 13(3), 91-97. https://doi.org/10.5114/nan.2018.81249

Ruck, C. A., Bigwood, J., Staples, D., Ott, J., \& Wasson, R. G. (1979). Entheogens. Journal of Psychedelic Drugs, 11(1-2), 145-146. https://doi.org/10.1080/02791072.1979.10472098

Ruffell, S., Netzband, N., Bird, C., Young, A. H., \& Juruena, M. F. (2020). The pharmacological interaction of compounds in ayahuasca: a systematic review. Brazilian Journal of Psychiatry, 42(6), 646-656. https://doi.org/10.1590/1516-4446-2020-0884

Saldanha, A. (2007). Psychedelic Whiteness. In A. Saldanha (Ed.), Psychedelic White: Goa trace and the viscosity of race (pp. 11-20). Minneapolis, MI: University of Minnesota Press.

Sessa, B. (2017). The 21st century psychedelic renaissance: heroic steps forward on the back of an elephant. Psychopharmacology, 235(2), 551-560. https://doi.org/10.1007/s00213-0174713-7

Shafer, J. (2010, June 21). How Time and Life magazines helped turn America on to LSD. Slate Magazine. https://slate.com/news-and-politics/2010/06/how-time-and-life-magazineshelped-turn-america-on-to-lsd.html.

Sheline, Y. I., Barch, D. M., Price, J. L., Rundle, M. M., Vaishnavi, S. N., Snyder, A. Z., Mintun, M. A., Wang, S., Coalson, R. S., \& Raichle, M. E. (2009). The default mode network and self-referential processes in depression. Proceedings of the National Academy of Sciences, 106(6), 1942-1947. https://doi.org/10.1073/pnas.0812686106

Simon, R., \& Engström, M. (2015). The default mode network as a biomarker for monitoring the therapeutic effects of meditation. Frontiers in Psychology, 06. https://doi.org/10.3389/fpsyg.2015.00776

Smigielski, L., Scheidegger, M., Kometer, M., \& Vollenweider, F. X. (2019). Psilocybin-assisted mindfulness training modulates self-consciousness and brain default mode network connectivity with lasting effects. NeuroImage, 196, 207-215. https://doi.org/10.1016/j.neuroimage.2019.04.009 
Soibelman, T. (1995). "My father and my mother, show me your beauty": ritual use of ayahuasca in Rio De Janeiro (thesis).

Stamets, P. (1996). In Psilocybin mushrooms of the world: an identification guide (pp. 11-15). essay, Ten Speed Press.

Williams, M. T., Gooden, A. M., \& Davis, D. (2012). African Americans, European Americans, and pathological stereotypes: An African-centered perspective.

In G. R. Hayes \& M. H. Bryant (Eds.), Psychology of culture. Hauppauge, NY: Nova Science Publishers.

Yeshurun, Y., Nguyen, M., \& Hasson, U. (2021). The default mode network: where the idiosyncratic self meets the shared social world. Nature Reviews Neuroscience, 22(3), 181192. https://doi.org/10.1038/s41583-020-00420-w

Zhang, R., \& Volkow, N. D. (2019). Brain default-mode network dysfunction in addiction. NeuroImage, 200, 313-331. https://doi.org/10.1016/j.neuroimage.2019.06.036 